\title{
CAFFEINE CONTENT OF CONVENTIONAL AND NON CONVENTIONAL FOODS ON THE HUNGARIAN MARKET
}

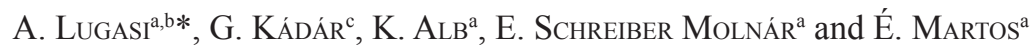 \\ ${ }^{a}$ National Institute for Food and Nutrition Science, H-1097 Budapest, Albert Flórián út 3/a. Hungary \\ ${ }^{\mathrm{b}}$ Budapest Business School, College of Commerce, Catering and Tourism, Department of Catering, \\ H-1054 Budapest, Alkotmány utca 9-11. Hungary \\ ${ }^{\mathrm{c} E o ̈ t v o ̈ s ~ L o r a ́ n d ~ U n i v e r s i t y, ~ F a c u l t y ~ o f ~ S c i e n c e, ~ C h e m i s t r y ~ D o c t o r a l ~ S c h o o l, ~}$ \\ H-1117 Budapest, Pázmány Péter sétány 1/a. Hungary
}

(Received: 19 August 2013; accepted: 3 March 2014)

\begin{abstract}
Caffeine content of 377 food samples obtained from the Hungarian market was measured by a validated HPLC technique. The highest caffeine levels were observed in different instant coffees $(3954 \pm 2355 \mathrm{mg} / 100 \mathrm{~g})$ and ground coffee beans $(1634 \pm 389 \mathrm{mg} / 100 \mathrm{~g})$. Significant amount of caffeine could be detected in energy drinks $(119 \mathrm{mg}$ in $100 \mathrm{ml}$ at the highest end). The caffeine content of different coffee drinks varied between 40 and $203 \mathrm{mg} / 100 \mathrm{ml}$. Significant amount of caffeine could be measured in special instant coffees called 2 in 1 and 3 in 1 (120 mg per serving at the highest end), cacao powders (125 mg in $100 \mathrm{~g}$ ), in chocolates (on average, $16.1 \mathrm{mg}$ and $52.5 \mathrm{mg}$ in $100 \mathrm{~g}$ milk and dark chocolate, respectively), breakfast cereals (between 5.7 and $15.8 \mathrm{mg}$ per $100 \mathrm{~g}$ ), and ice creams (1.7-24.8 $\mathrm{mg}$ in $100 \mathrm{~g}$ ).

Keywords: caffeine, coffee, energy drink, chocolates, teas
\end{abstract}

Caffeine (1,3,7-trimethyl-1H-purine-2,6(3H,7H)-dione) is a bitter, white crystalline xanthine alkaloid that is the most widely used psychoactive drug in the world. Some 60 plant species, including coffee, contain caffeine, distributed among seven plant families, acting as a natural pesticide that cramps and kills various insects and herbivores (NATHANSON, 1984).

Caffeine is found in coffee beans (Coffea arabica L., Coffea canephora Pierre ex Froehn. /robusta/, 0.7-3.2\%), tea leaves (Camellia sinensis Kuntze, 1.5-6\%), cacao beans (Theobroma cacao L., 0.4-0.8\%), cola beans (Cola nitida A. Chev., Cola acuminate Schott \& Endl., 2-3.5\%), guarana seeds (Paullinia cupana H.B. \& K., 2.5-7.5\%), and yerba mate leaves (Ilex paraguariensis A. St.-Hil., $0.7-1.7 \%$ ) as it is produced naturally in the beans and leaves of the plants (Kovacs \& Mela, 2006; Lee \& Balick, 2006; Dellacassa et al., 2007; FriedMAN, 2007). Some caffeine sources like coffee and cacao beans, guarana seeds, tea leaves contain also theobromine and theophylline, other alkaloids in the xanthine group (PIzzA et al., 1999).

Caffeine is also found in different food products manufactured with these natural sources like coffee drinks, soft drinks, chocolates, cocoa, and cacao based sweets, and so on. Caffeine is also used in other products, such as soda, energy drinks, and some pain relievers (FRARY et al., 2005). The levels of caffeine can vary widely in these products depending on the strength of the preparation, as in the case of tea and coffee, or the amount that is added exogenously, as in the case with soda and energy drinks.

\footnotetext{
* To whom correspondence should be addressed. Phone: +36-1-374-6266; e-mail: lugasi.andrea@kvifk.bgf.hu
} 
Because of caffeine's ubiquity, caffeine is rarely thought of as a problematic drug. The primary effect of caffeine is to relieve fatigue and enhance mental performance. Although there is no human requirement for caffeine, even low doses of caffeine (12.5 to $100 \mathrm{mg}$ ) improve cognitive performance and mood (SMIT \& ROGERS, 2000). The psychological effects of caffeine are two-sided. Low doses produce stimulation, which is often sensed as desirable (Daly \& Fredholm, 1998). Caffeine increases alertness, can elevate mood and reduces fatigue (Rogers \& Dernoncourt, 1997; Smith, 2002). Normal consumption improves performance on tasks that require alertness (Sмiтh, 2002). Although it is suggested by scientific evidence that high consumption is associated with better performance, especially in older people, the effect on more complex cognitive tasks is difficult to assess (SMITH, 2002).

The total daily intake, as well as the leading food source of caffeine, varies throughout the world. The majority of the human studies that have been conducted in the past decade has demonstrated that moderate $(<400 \mathrm{mg} / \mathrm{d})$ caffeine consumption causes no significant health risks to most consumers (NAWROT et al., 2003).

The aim of the present study is to identify the caffeine containing common and uncommon foods and drinks including energy drinks on the Hungarian market, investigate their caffeine content and develop a caffeine database including the types and forms of caffeine containing beverages and foods. The next step will be a scientific estimation of the dietary intake of caffeine among the adult population using a 3-day dietary record obtained in the Hungarian Diet and Nutritional Status Survey (OTAP2009), results of which will be published later. All parts of this study were done at the National Institute for Food and Nutrition Science.

\section{Materials and methods}

\subsection{Samples}

A total of 377 samples were purchased as allowed by market availability in the central zone of Hungary. Samples were collected between November 2009 and October 2011. Labels on the packaging contained only qualitative information about the ingredients, without mentioning the caffeine content except for soft drinks called energy drinks, which have caffeine content $\geq 150 \mathrm{mg} \mathrm{l}^{-1}$ according to EU legislation (EC, 2002).

Eight different coffee drinks were prepared by traditional coffee brewing technique as percolating or with new types of coffeemakers with randomly chosen brands of ground coffee.

\subsection{Reagents and materials}

All solvents were of high performance liquid chromatography (HPLC) grade (MERCK, Darmstadt, Germany). HPLC degree water (conductivity $=0.055 \mu \mathrm{S}$ ) was made by ELGA water purifying system (ELGA, High Wycombe, UK). The ammonium hydroxide solution (containing 25\% ammonia in water) was the reagent grade (Molar Chemicals, Budapest, Hungary). Pure caffeine standard was purchased from Sigma-Aldrich, St. Louis, MO. Caffeine was dissolved in methanol:water (30:70) mixture to form standard solution. This caffeine stock solution of $1000 \mathrm{mg} \mathrm{l}^{-1}\left(10.0 \mu \mathrm{g} \mathrm{ml}^{-1}\right)$ was prepared freshly on the day of analysis. Work solutions for standard curve were prepared by diluting stock solution with 
mobile phase where caffeine content ranged from 5 to $10 \mathrm{mg}$ per litre. The standard curve had a linear correlation of 0.999 .

\subsection{Sample preparations}

Appropriate amount of liquid samples like cola, ice tea, energy drink beverages, ice coffees, chocolate drinks, and ready-to-drink teas and coffees were diluted with methanol:water (30:70), ultrasonicated for $5 \mathrm{~min}$ in order to eliminate carbon-dioxide, then filled up to a final volume of $100 \mathrm{ml}$ with methanol:water (30:70).

Home-made tea and coffee beverages were prepared according to direction of use on the product label. One filter of tea or one sachet of instant coffee was precisely weighted into the extraction vessel with $200 \mathrm{ml}$ hot water $\left(\sim 80^{\circ} \mathrm{C}\right)$ and shaken for a fixed time of $5 \mathrm{~min}$, then handled as liquid sample, see above. Homemade coffee drinks were prepared with different traditional Hungarian or new type coffeemakers using such amount of ground coffee and water as described in the operating instructions of the machine. Hungarian coffeemakers prepare very strong drinks as a consequence of percolating, which means that the boiling water has been pressed through ground coffee that is located between two metal filters.

In case of solid samples at least $100 \mathrm{~g}$ food was homogenized prior to measurement. Depending on the expected caffeine level 1-20 g of homogenized ground coffee beans, chocolate, cake, cream, pudding and cocoa powder, and other solid samples were weighted into a stirring vessel with $5 \mathrm{ml}$ of $8 \%$ ammonia solution, covered by hourglass and stirred for $5 \mathrm{~min}$. Then the solution was kept in a water bath at $78^{\circ} \mathrm{C}$ for $15 \mathrm{~min}$. After $30 \mathrm{~min}$ of cooling, samples were washed with methanol:water (30:70) into $100 \mathrm{ml}$ volumetric flasks and filled up. Where it was appropriate, samples were centrifuged before dilution to $100 \mathrm{ml}$. After 30 min sample solutions were filtered (Macherey-Nagel, Düren, Germany, $15 \mathrm{~cm} \mathrm{Ø).}$

Before injection into HPLC, all sample solutions were filtered with $0.45 \mu \mathrm{m}$ pore size filter (La-Pha-Pack, Germany, Profill Plus PTFE).

\subsection{Apparatus and conditions}

For the HPLC analysis a Thermo Surveyor Plus (ThermoFisher Scientific, Waltham, USA) system was used that consists of an autosampler (Surveyor Autosampler Plus), a pump (Surveyor LC Pump Plus), and a diode array detector (Surveyor PDA Plus) unit. The column and guard column were Thermo Hypersil BDS (ThermoFisher Scientific, Waltham, USA). The eluent was a mixture of methanol:water (30:70), and an isocratic elution was used. The injected amount of the sample was $2 \mu$ l. Further chromatographic conditions: column heat control: $30{ }^{\circ} \mathrm{C}$, flow rate: $0.8 \mathrm{ml} \mathrm{min}{ }^{-1}$. Caffeine eluted around $15 \mathrm{~min}$ and was detected at $272 \mathrm{~nm}$. No peaks interfered with the peak of interest. For the qualification and quantification of caffeine a standard curve mentioned in section 1.2. and a Chromquest 4.2.34 as analysing software was used.

\subsection{Recovery studies and quality assurance}

Recoveries were determined by spiking a soft drink with known caffeine content, in triplicate, with known amounts of caffeine at final concentrations between 60 and $250 \mathrm{mg} \mathrm{l}^{-1}$. A FAPAS (The Food and Environment Research Agency, Sand Hutton, York, UK) test material as cola drink (T0389) was also measured in September 2010. 


\section{Results and discussion}

\subsection{Quality of the analytical measurement}

The analytical methodology revealed good linearity, sensitivity, exactitude, and precision. The evaluated range was between $0.12 \mu \mathrm{g}$ and $1.2 \mu \mathrm{g}$ of caffeine, of the amount injected in $15 \mu \mathrm{l}$ of standard solutions with concentrations of 8 and $80 \mathrm{mg} \mathrm{l}^{-1}$, respectively. Correlation coefficient $\left(\mathrm{r}^{2}\right)$ was 0.9802 . Limits of quantification varied between $0.5 \mathrm{mg} \mathrm{l}^{-1}$ and $7.0 \mathrm{mg} \mathrm{l}^{-1}$.

Recovery values were between $94.7 \%$ and $103.5 \%$ for caffeine as it can be seen in Table 1. Intra-day repeatability was $6.3 \%$ for caffeine at $120 \mathrm{mg} \mathrm{l}^{-1}$. The interday repeatability ranged between $3.2 \%$ and $9.6 \%$. Measured value of caffeine in cola drink as FAPAS test was $106 \mathrm{mg} \mathrm{l}^{-1}$, while satisfactory range was between $89-122 \mathrm{mg} \mathrm{l}^{-1}$. Results have shown a good quality of the method for caffeine determination.

\begin{tabular}{lc}
\multicolumn{2}{c}{ Table 1. Recovery values of caffeine for different matrices } \\
\hline Matrix & Recovery \% (range) \\
\hline Caffeine free coffee & $97.9(93.2 ; 99.2)$ \\
Coffee with reduced caffeine level & $103.5(97.3 ; 106.1)$ \\
Milk chocolate & $97.9(96.1 ; 99,3)$ \\
Energy drink & $99.4(96.3 ; 102.6)$ \\
Black tea & $94.7(90.2 ; 99.4)$ \\
\hline
\end{tabular}

\subsection{Caffeine content of different food items}

2.2.1. Beverages. The caffeine levels of beverages are summarized in Table 2. Commercially available ice teas have very low levels of caffeine ranging between 0.3 and $5.9 \mathrm{mg}$ in $100 \mathrm{ml}$ showing that these products contain very small amount of tea (Camelia sinensis) extract.

Table 2. Caffeine content of commercially available beverages, $\mathrm{mg} / 100 \mathrm{ml}$

\begin{tabular}{|c|c|c|c|c|c|}
\hline Food product & $\begin{array}{c}\text { Number of } \\
\text { samples }\end{array}$ & Average & $\pm \mathrm{SD}$ & Min & Max \\
\hline Ice tea drinks & 4 & 3.13 & 3.12 & 0.3 & 5.9 \\
\hline Energy drinks & 43 & 35.2 & 25.4 & 0 & 119 \\
\hline Soft drinks with caffeine & 9 & 11.4 & 4.6 & 2.7 & 17.4 \\
\hline Coffee drinks in cans & 5 & 17.5 & 9.8 & 7.2 & 27.2 \\
\hline Cacao drinks & 3 & 2.4 & 0.3 & 2.1 & 2.7 \\
\hline
\end{tabular}

Most of the soft drinks called energy drinks have very high levels of caffeine, well past the obligatory claim on the label. Directive 2002/67/EC establishes that beverages containing caffeine from whatever source (including natural and synthetic caffeine) in excess of 
$150 \mathrm{mg}^{-1}$ must bear the message "High Caffeine Content" followed by the amount of caffeine expressed by milligrams per $100 \mathrm{ml}$ on the label (EC, 2002). The majority of the products have caffeine around $30 \mathrm{mg}$ per $100 \mathrm{ml}$ meaning that consuming one serving (250 $\mathrm{ml}$ ) of energy drink results in a $90 \mathrm{mg}$ caffeine intake. Zero or very low levels could be detected in four products, where "caffeine free" was claimed on the label and was no caffeine or caffeine containing plant extracts included in the ingredients. The highest level of caffeine, $119 \mathrm{mg}$ in $100 \mathrm{ml}$, which corresponds to nearly $300 \mathrm{mg}$ in one serving (one can), was detected in two samples. Referring to the side effects of caffeine, especially in children and teenagers, this level of caffeine seems to be unsafe in case of regular consumption.

Soft drinks, as different cola drinks have caffeine around $10 \mathrm{mg}$ in $100 \mathrm{ml}$. The highest level measured was $17 \mathrm{mg}$ in $100 \mathrm{ml}$. There are some coffee drinks sold in cans on the Hungarian market but these products are of different country origins. The caffeine content of coffee drinks varied between 7.2 and $27.2 \mathrm{mg}$ in $100 \mathrm{ml}$ while the average level was $17.5 \mathrm{mg}$. Cacao drinks sold in plastic bags or boxes have milk, sugar, and cacao as main ingredients. The amount of cocoa powder is not labelled but it can not be very high because of the caffeine content of these drinks are very low, varying between 2.1 and $2.7 \mathrm{mg}$ in $100 \mathrm{ml}$.

The caffeine content of home-made beverages shows a very wide range depending on the caffeine sources and the preparation techniques (see Table 3). The caffeine content of regular home-made coffee drinks varied between 41 and $203 \mathrm{mg}$ in one serving, with an average of $73.1 \mathrm{mg}$.

The caffeine content of tea drinks tested in this investigation ranged from 4.1 on the lower end, in the case of a rooibos tea, to $48.6 \mathrm{mg}$ per serving detected in Greenfield Golden Dragon black tea. It seems that the average caffeine content of green and black teas are similar, ranging from 21.5 to $45.8 \mathrm{mg}$ per serving, and from 23.1 to $48.6 \mathrm{mg} / \mathrm{serving}$, respectively. White and red teas have lower levels of caffeine than black and green teas, while teas from different plant materials as fruits, rooibos (Aspalatus linearis), mate (Ilex paraguariensis) varied in a wide range from 4.1 to $42.8 \mathrm{mg}$ per serving.

Table 3. Caffeine content of home made beverages, $\mathrm{mg} / \mathrm{cup}^{*}$

\begin{tabular}{|c|c|c|c|c|c|}
\hline Food product & Number of samples & Average & $\pm \mathrm{SD}$ & Min & Max \\
\hline Coffee drinks & 8 & 73.1 & 53.8 & 41 & 203 \\
\hline Green teas & 12 & 30.5 & 8.2 & 21.5 & 45.8 \\
\hline Black teas & 9 & 30.6 & 7.9 & 23.1 & 48.6 \\
\hline White teas & 2 & - & - & 27.8 & 39.2 \\
\hline Red tea & 1 & - & - & - & 9.1 \\
\hline Other teas & 10 & 24.6 & 12.9 & 4.1 & 42.8 \\
\hline
\end{tabular}

*Drinks were prepared according to package directions in case of tea drinks or according to common, traditional drink preparation methods in the case of coffee drinks.

2.2.2. Coffee, cacao, and pudding powder. Caffeine content of different solid food items are summarized in Table 4. In case of ground coffee beans the highest level was detected in a pure Coffea robusta sample $(2487 \mathrm{mg} / 100 \mathrm{~g})$, and the lowest in a pure Coffea arabica bean 
$(1289 \mathrm{mg} / 100 \mathrm{~g})$. All the other samples were mixtures of these two varieties and represent a not very wide range of caffeine content between $1484-1567 \mathrm{mg} / 100 \mathrm{~g}$. The average caffeine level of commercially available coffee mixtures with reduced caffeine level was $660 \mathrm{mg} /$ $100 \mathrm{~g}$, while caffeine in samples labelled as caffeine free was below $70 \mathrm{mg} / 100 \mathrm{~g}$. Codex Alimentarius Hungaricus 2-86 Directive on "Coffee, coffee mixes, coffee substitutes and other coffee products" gives the quality parameters of the coffees, including their caffeine level. The caffeine content of normal coffee, coffee with reduced caffeine level, and decaffeinated coffees should be more than $0.8 \%$, less than $0.8 \%$, and less than $0.08 \%$, respectively (Codex Alimentarius Hungaricus, 1986). All samples investigated in this study correspond to the directive.

Instant coffees contain high levels of caffeine, the average value is $3954 \mathrm{mg} / 100 \mathrm{~g}$, the lowest and the highest are 2418 and $8079 \mathrm{mg} / 100 \mathrm{~g}$, respectively. Recently, several coffee products like 2 in 1 and 3 in 1 are available on the market. Consumers believe that these products contain no or very low levels of caffeine. Present results refute this concept because instant coffees type 3 in 1 and 2 in 1 contain at least $74 \mathrm{mg}$ caffeine in one serving, while the best formula can be characterized by $120 \mathrm{mg}$ caffeine in one sachet.

Cacao powder showed $125 \mathrm{mg}$ caffeine in $100 \mathrm{~g}$ on average, while instant cacao powders had significantly lower amounts of caffeine (between 25.0 and $43.9 \mathrm{mg}$ in $100 \mathrm{~g}$ ) primarily as a result of the addition of different other ingredients like sugar and vitamin premixes. Pudding powders with cacao show $30.6 \mathrm{mg}$ average caffeine level in $100 \mathrm{~g}$ powder. The lowest and the highest levels were 15.9 and $50.0 \mathrm{mg}$ in $100 \mathrm{~g}$, respectively.

2.2.3. Chocolates. There is no doubt that the caffeine content of different chocolates depends on the cacao level of the given product. The composition of these products is regulated by two Codex Alimentarius directives regarding cacao and chocolate products (Codex Alimentarius Hungaricus, 2000) 1-3-2000/36, and confectionary products (CodeX Alimentarius Hungaricus, 1984), 2-84. The basic difference between chocolates and confectionary products is the presence or absence of cacao butter. Products prepared without cacao butter should not be labelled as chocolate. However, in this survey chocolates and confectionary products that look like chocolates are investigated together, because the caffeine level of the products does not seem to be dependent on the cacao butter content. Therefore, all the distinction applied here was based on the absence or presence of milk or milk like ingredients. Two samples represented the white chocolates, where caffeine content was very low, 1.2 and $11.5 \mathrm{mg}$ in $100 \mathrm{~g}$. One white chocolate with added green tea extract was also investigated: the caffeine level of this product was very high $(75.3 \mathrm{mg}$ in $100 \mathrm{~g})$ because green tea is a very good source of caffeine.

The average caffeine level of 30 different milk chocolates was $16.1 \mathrm{mg}$ in $100 \mathrm{~g}$, while the lowest and the highest were 5.8 and $26.7 \mathrm{mg}$ per $100 \mathrm{~g}$, respectively. Dark chocolates represented higher average caffeine level at $52.5 \mathrm{mg}$, while the lowest and highest were 13.1 and $117 \mathrm{mg}$ in $100 \mathrm{~g}$ product. Eleven chocolate specialities showed an average $16.8 \mathrm{mg}$ caffeine level. Hungarian Christmas specialities (Hungarian name is szaloncukor) produced and consumed only around Christmas and used for the decoration of Christmas trees had only $3.68 \mathrm{mg}$ caffeine in $100 \mathrm{~g}$. 
Table 4. Caffeine content of commercially available solid foods, $\mathrm{mg} / 100 \mathrm{~g}$ (except for instant coffees 2 in 1 and 3 in 1 where $\mathrm{mg} /$ serving of prepared beverage)

\begin{tabular}{|c|c|c|c|c|c|}
\hline Food product & $\begin{array}{l}\text { Number of } \\
\text { samples }\end{array}$ & average & $\pm \mathrm{SD}$ & Min & Max \\
\hline \multicolumn{6}{|l|}{ Ground coffee powders } \\
\hline with normal caffeine level & 7 & 1634 & 389 & 1289 & 2487 \\
\hline reduced caffeine level & 49 & 660 & 96 & 320 & 795 \\
\hline caffeine free & 48 & 59 & 7.2 & 38.2 & 70.5 \\
\hline Instant coffees, normal & 5 & 3954 & 2355 & 2418 & 8079 \\
\hline Instant coffees, 2 in 1 and 3 in 1 & 15 & 73.9 & 30.0 & 9.3 & 120 \\
\hline Cacao powders & 6 & 125 & 40.9 & 57 & 163 \\
\hline Cacao powders, instant & 6 & 31.5 & 6.7 & 25.0 & 43.9 \\
\hline Pudding powders with cacao & 5 & 30.6 & 16.0 & 15.9 & 50.0 \\
\hline White chocolates, traditional & 2 & - & - & 1.2 & 11.5 \\
\hline with green tea extract & 1 & . & - & & 75.3 \\
\hline Milk chocolates & 30 & 16.1 & 4.5 & 5.8 & 26.7 \\
\hline Dark chocolates & 23 & 52.5 & 26.3 & 13.1 & 117 \\
\hline Chocolate specialities & 11 & 16.8 & 17.8 & 0.96 & 50.6 \\
\hline $\begin{array}{l}\text { Hungarian Christmas chocolate candy } \\
\text { specialities }\end{array}$ & 13 & 3.68 & 1.18 & 1.9 & 6.3 \\
\hline Biscuits, wafers & 19 & 6.6 & 4.3 & 0.8 & 15.8 \\
\hline Breakfast cereals with cacao & 4 & 10.2 & 4.6 & 5.7 & 16.5 \\
\hline Puddings & 2 & - & - & 4.8 & 5.9 \\
\hline Cottage cheese desserts & 6 & 14.2 & 7.0 & 3.9 & 23.4 \\
\hline Peanut creams & 6 & 9.2 & 5.6 & 3.4 & 17.9 \\
\hline Ice creams & 5 & 7.6 & 9.8 & 1.7 & 24.8 \\
\hline Others sweets & 8 & 3.3 & 2.74 & 1.7 & 9.2 \\
\hline
\end{tabular}

2.2.4. Biscuits, wafers, breakfast cereals, other sweet products with cacao. Biscuits and wafers investigated in this survey contained cacao or chocolate at different levels. In most cases this level was not indicated on the product label. The 19 biscuits examined had $6.6 \mathrm{mg}$ caffeine in $100 \mathrm{~g}$ on average, the lowest and highest levels were 0.8 and $15.8 \mathrm{mg}$ in $100 \mathrm{~g}$, respectively. Breakfast cereals that are often consumed by children contained caffeine between 5.7 and $15.8 \mathrm{mg}$ per $100 \mathrm{~g}$. Ready to eat puddings that are produced with milk, starch, sugar, and cacao powder as main ingredients contained very low levels of caffeine, between 4.8 and $5.9 \mathrm{mg}$ per $100 \mathrm{~g}$.

In Hungary, chocolate containing desserts based on cottage cheese, like chocolate coated cottage cheese fingers, are very popular, especially among children. Six different items represented the cottage cheese dessert in this survey. These products contained caffeine between 3.9 and $23.4 \mathrm{mg}$ per $100 \mathrm{~g}$, the average level was $14.2 \mathrm{mg}$. Although the main 
ingredient of the original peanut cream is dry roasted peanut, in some popular commercial versions cacao powder or chocolate can be found, as well. In the six peanut creams flavoured by cacao or chocolate investigated here, a significant amount of caffeine was found, with the average level at $9.2 \mathrm{mg}$, the lowest and highest levels 3.4 and $17.9 \mathrm{mg}$ per $100 \mathrm{~g}$. Ice creams containing cacao powder in the cream and/or coated with chocolate can be sources of caffeine as the present data pointed out. Five different ice creams contained caffeine between $1.7 \mathrm{mg}$ and $24.8 \mathrm{mg}$ in $100 \mathrm{~g}$. Some other sweets based on cookies, waffles, and sponge-cakes had low levels of caffeine as indicated in Table 4.

\section{Conclusions}

In the present study, we developed a comprehensive caffeine database, which contained beverages and solid foods available on the Hungarian market. Caffeine content data of different food items investigated in the present study are comparable to those published by other authors (Shively \& TARKA, 1984; CAMARGO et al., 1999, CAUdle et al., 2001; McCuSKer et al., 2003, 2006a; 2006b; Pena et al., 2005; Chou \& Bell, 2007; Olmos et al., 2009; Heckman et al., 2010). These data show that there are some special caffeine sources like cakes, biscuits or cottage cheese based desserts containing cocoa or chocolate, but it is supposed that these foods do not contribute at a high level in the intake of caffeine.

It is important to mention here that in September 2011 a new legislation as the CIII. Act on Public Health Tax came into force in Hungary. The aim of this rule is to hinder the consumption of unhealthy food and to promote the healthy nutrition. According to this law tax is imposed on foods having high level of unhealthy food components like sugar, salt, and caffeine. Referring to the last one in operation of the Act, drinks belonging to 2009 and 2202 costume tariff numbers are called energy drinks when 1) the product contains methyl-xanthine (as additional or natural) and taurine, and methyl-xanthine level $>1 \mathrm{mg} / 100 \mathrm{ml}$, or taurine $>100 \mathrm{mg} \mathrm{ml}^{-1}$, 2) the product contains methyl-xanthine $>15 \mathrm{mg} / 100 \mathrm{ml}$. Since the CIII. Act came into force, energy drinks have been imposed public health tax and food manufacturers have been looking for the way to avoid it. The most practical possibility is to modify the composition of energy drinks that the authors have recognized in the last two years. That is the reason why the caffeine content of some special products on the market could be modified since the survey was done.

\section{References}

Camargo, M.C., Toledo, M.C. \& Farah, H.G. (1999): Caffeine daily intake from dietary sources in Brazil. Food Addit. Contam., 16, 79-87.

Caudle, A.G., Gu, Y. \& Bell, L.N. (2001): Improved analysis of theobromine and caffeine in chocolate food products formulated with cocoa powder. Food Res. Int., 34, 599-603.

Chou, K.H. \& BelL, L.N. (2007): Caffeine content of prepackaged national-brand and private-label carbonated beverages. J. Food Sci., 72, 337-342.

Codex Alimentarius Hungaricus (2000): Emberi fogyasztásra szánt kakaó- és csokoládétermékek. (Cacao and chocolate products intended for human consumption.) Order no. 1-3-2000/36.

Codex Alimentarius Hungaricus (1984): Édesipari termékek. (Confectionery products, waffles and biscuits.) Directive 2-84

Codex Alimentarius Hungaricus (1986): Kávé, kávékeverék, pótkávé és egyéb kávékészítmények. (Coffee, coffee mixes, coffee substitutes and other coffee products.) Directive 2-86 
Daly, J.W. \& Fredholm, B.B. (1998): Caffeine - an atypical drug of dependence. Drug Alc. Depend., 51, $199-206$. Dellacassa, E.C., Cesio, V., VÁzquez, A., Echeverry, S., Soule, S., Ferreira, F. \& Heinzen, H. (2007): Yerba mate. Historia, uso y propiedades. (Mate tea. History, usage and properties.) Revista de la Asociación de Química y Farmacia del Uruguay, 51, 1620.

EC (2002): Commission Directive 2002/67/EC of 18 July 2002 on the labeling of foodstuffs containing quinine, and of foodstuffs containing caffeine. Off. J. Eur. Comm., L191, 20-21.

Frary, C.D., Johson, R.K. \& Wang, M.Q. (2005): Food sources and intakes of caffeine in the diets of persons in the United States. J. Am. Diet. Assoc., 105, 110-113.

Friedman, M. (2007): Overview of antibacterial, antitoxin, antiviral, and antifungal activities of tea flavonoids and teas. Mol. Nutr. Food Res., 51, 116-134.

Heckman, M., Weil, J. \& Gonzalez Demejia, E. (2010): Caffeine (1, 3, 7-trimethylxanthine) in foods: A comprehensive review on consumption, functionality, safety, and regulatory matters. J. Food Scie, 75, $77-87$.

Kovacs, E.M. \& Mela, D.J. (2006): Metabolically active functional food ingredients for weight control. Obes. Rev., 7, 59-78.

LeE, R.A \& BALick, M.J. (2006): Rx: Caffeine. Explore, 2, 55-59.

McCusker, R.R., Fuehrlein, B., Goldberger, A., Gold, M.S. \& Cone, E.J. (2006A): Caffeine content of decaffeinated coffee. J. Anal. Toxicol., 30, 611-613.

McCusker, R.R., Goldberger, B.A. \& Cone, E J. (2003): Caffeine content of specialty coffees. J. Anal. Toxicol., 27, 520-522.

McCusker, R.R., Goldberger, B.A. \& Cone, E.J. (2006B): Caffeine content of energy drinks, carbonated sodas, and other beverages. J. Anal. Toxicol., 30, 112-114.

Nathanson, J.A. (1984): Caffeine and related methylxanthines: possible naturally occurring pesticides. Science, 226, 184-187.

Nawrot, P., Jordan, S., Eastwood, J., Rotstein, J., Hugenholtz, A. \& Feely, M. (2003): Effects of caffeine on human health. Food Addit. Contam., 20, 1-30.

Olmos, V., Bardoni, N., Ridolfi, A.S. \& Villaamil Lepori, E.C. (2009): Caffeine levels in beverages from Argentina's market: application to caffeine dietary intake assessment. Food Addit. Contam. A., 26, $275-281$.

Pena, A., Lino, C. \& Silveira, M.I.N. (2005): Survey of caffeine levels in retail beverages in Portugal. Food Addit. Contam., 22, 91-96.

Pizza, C., Rastrelli, L., Totaro, K. \& De Simone, F. (1999): Paullinia cupana (guarana): determinazione degli alcaloidi xantinici per la valutazione della qualita' di prodotti base di guarana'. (Paullinia cupana (guarana): determination of xanthine alkaloids in order to set the value of guarana based products.) -in: Il Guarana' degli Indios Satere'-Maue', Instituto Italo-Latinoamericana, Rome: Serie Scienza, 13, 13-22.

Rogers, P.J. \& Dernoncourt, C. (1997): Regular caffeine consumption: a balance of adverse and beneficial effects for mood and psychomotor performance. Pharm. Biochem. Behav., 59, 1039-1045.

Shively, C.A. \& TARKA, S.M. (1984): Methylxanthine composition and consumption patterns of cocoa and chocolate products. Prog. Clin. Biol. Res., 158, 149-178.

Smit, H.J. \& Rogers, P.J. (2000): Effects of low doses of caffeine on cognitive performance, mood and thirst in low and higher caffeine consumers. Psychopharmacology, 152, 167-173.

Smith, A. (2002): Effects of caffeine on human behaviour. Food Chem. Tox., 40, 1243-1255. 